\title{
CON-CRIATIVIDADE EM ROMBACH E MESTRE ECKHART
}

\author{
Co-creativity by Rombach and Master Eckhart \\ Co-Criatividad en Rombanch y Master Eckhart
}

Enio Paulo Giachini

\begin{abstract}
Resumo: Partindo da fenomenologia estrutural e respingando no pensamento medieval de Mestre Eckhart, esse texto aborda a questão da criatividade e co-criatividade. Trata-se de uma "categoria" central da fenomenologia e, dentre outras chaves de abordagem e de entrada na fenomenologia estrutural, é um instrumental para descrição de mundo, mundo do espírito. A criatividade não é a mera inovação tecnológica ou criação de novos produtos, serviços ou de qualquer outro objeto. É a descoberta e exercício de uma nova dimensão de vida. A irrupção de uma nova dimensão eleva junto consigo todo um universo de elementos inerentes ao humano, dando-lhes novo sentido.
\end{abstract}

Palavras-chave: criatividade, co-criatividade, ontologia do fazer, estrutura.

\begin{abstract}
Starting from the structural phenomenology and spreading in the medieval thought of Master Eckhart, this text approaches the question of the creativity and co-creativity. It is a central "category" of phenomenology and, among other keys to approach and entry into structural phenomenology, is an instrument for the description of the world, the world of the spirit. Creativity is not mere technological innovation or creation of new products, services or any other object. It is the discovery and exercise of a new dimension of life. The irruption of a new dimension brings together a whole universe of elements inherent to the human being, giving them new signification.
\end{abstract}

Keywords: creativity, co-creativity, ontology of the performance, structure.

Resumen: Partiendo de la fenomenología estructural y salpicando en el pensamiento medieval del Maestro Eckhart, este texto aborda la cuestión de la creatividad y la co-creatividad. Se trata de una "categoria" central de la fenomenología y, entre otras claves de abordaje y de entrada en la fenomenología estructural, es un instrumental para la descripción de mundo, mundo del espíritu. La creatividad no es la mera innovación tecnológica o la creación de nuevos productos, servicios o de cualquier otro objeto. Es el descubrimiento y el ejercicio de una nueva dimensión de vida. La irrupción de una nueva dimensión eleva junto a él todo un universo de elementos inherentes al humano, dándoles nuevo sentido.

Palabras clave: Creatividad, Co-creatividad, Ontología del hacer, Estructura.

\section{Introdução}

A "categoria" da criatividade é um conceito central da fenomenologia estrutural, pensada sobretudo por H. Rombach no final do século passado. Com certa tranquilidade também é possível ver esse mesmo processo em pensadores como Nicolau de Cusa e Mestre Eckhart. A partir de modos de abordagem distintos, o destino desses percursos se torna muito semelhante.

Esse texto se propõe abordar e descrever sumariamente o conceito de criatividade a partir do livro Der Ursprung, de Heinrich Rombach (1994) e do $\mathrm{n}^{\circ} 23$ das Conversações espirituais, de Mestre Eckhart (1994). Tanto um quanto outro, procuram elevar-se da ontologia do fazer para alcançar o âmbito do ser. Todavia, o itinerário não passa pela ascética, o puro e simples abdicar do imediato e próximo, do fazer e operar, mas, muito pelo contrário, pela apropriação plena e superação da ontologia do fazer. A dimensão do criativo surge quando se esgotam as possibilidades de um fazer bem concreto numa caminhada de crescimento num campo de atividade. O nascimento de Deus na alma, a obra interior surge quando se consegue o exercício pleno do interior em qualquer das obras exteriores. Não há um abandono das obras exteriores, para priorizar um suposto interior, mas um conectar todo fazer exterior num movimento de transcendência e superação de si seguindo uma intuição prévia "interior".

\section{Co-criatividade não é inovação do fazer}

Na análise positiva que se faz hoje desse fenômeno, compreende-se por criatividade a capacidade de inovação e inventividade. Essa análise vem pautada na praticidade e utilidade das abordagens e métodos de feitura e desempenho de processos e produtos. No Ocidente, via de regra, tem-se compreendido a criatividade a partir da ontologia do "fazer", e nesse sentido criatividade só pode ser vista como aquele produzir que "faz algo novo"; criar é fazer algo novo. Para se ter a impressão do criativo é preciso produzir novas formas, novas fórmulas, novas coisas e novos objetos... produtos novos. Toma-se a materialidade e a situação já existentes e, a partir daí, 'cria-se' algo de novo. Em nossa representação judaico-cristã de criação também concebemos a "criação" do mundo e do homem como feitos por Deus-criador. Do barro Deus fez o homem e lhe deu uma imagem. 
$\mathrm{Na}$ análise negativa dessa palavra, que é toda e qualquer tentativa que não se enquadre na escala da produção e do fazer, qualifica-se toda produção e inovação que seja disfuncional, que não tenha utilidade e emprego direto e imediato. Muitas artes, literatura e vida são qualificados aqui como "criativos" mas infrutíferos, inúteis.

Porém, tanto no fazer fecundo quanto no inútil já se dispõe de antemão de "criador, plano, material, forma, espaço, sentido e finalidade" (Rombach, 1994, p. 15) da criação. O fazer estabelece um arranjo desses elementos prévios e lhes dá um novo aviamento.

"Criativo, porém, só é aquele produzir que, junto com a coisa produzida cria igualmente uma nova dimensão para essa coisa e para coisas semelhantes" (Rombach, 1994, p. 15). Coisa, pensamos já saber o que é. Coisa é objeto, um algo, um ente, um abacaxi, uma pedra lápis-lazúli, um sapato... Mas quando se fala de dimensão, começamos já a ter mais dificuldade. Uma outra palavra para dizer dimensão é horizonte, regionalidade ou também essência (Wesen). Todavia, essas palavras não coincidem pura e simplesmente. A dimensão sempre é anterior e posterior à coisa. A arte se identifica e ao mesmo tempo se diferencia da obra de arte concreta. A arte é antes e depois da obra. É a condição de possibilidade para que haja algo assim como quadro, $5^{\text {a }}$ Sinfonia...

Para compreender o fenômeno da criatividade e da co-criatividade é necessário conseguir ver e experimentar essa diferença e identidade entre coisa e sua dimensão. Retomando a afirmação anterior de que para haver criatividade há que surgir nova dimensão, podemos perguntar agora: Já não nos descobrimos e sempre não nos encontramos inseridos inalienavelmente dentro de alguma dimensão? A dimensão da arte, da hortelania, da marcenaria, da política, do estudo... já não são dimensões prévias, dadas? O que será preciso inventar para ser criativo? Uma nova dimensão, mas o que poderia ser...? A arte de transportar-se telepaticamente para "outras terras", descobertas pela Nasa? Uma desconfiança: Será que naquilo que chamamos obviamente de coisa, da qual já sabemos e conhecemos, um abacaxi, uma pedra, um sapato, um quadro, não se inclui também o que chamamos de dimensão, a agricultura, a geologia, a artesania, a arte? Elas não têm, também elas, o modo de ser de ob-jeto? Mas, se for assim, o que significa então dimensão e nova dimensão? A abordagem dessas questão também nos levará a colocar em questão o que se compreende por coisa, ente.

Mas como surge nova dimensão? Surge por exemplo em uma conversão, na passagem de um modo de vida para outro, na realização plena e no esgotamento de uma possibilidade, onde surge o vazio e pode vir a irromper uma nova vida. Via de regra essa nova vida é experimentada como "graça", no âmbito da experiência do divino, nova dimensão é a experiência da graça.

A menor obra da graça é maior que todos os anjos em sua natureza. Santo Agostinho ${ }^{1}$ diz que uma obra da graça operada por Deus assim, por exemplo, quando ele converte um pecador em um homem bom - é maior do que se ele criasse um novo mundo (Eckhart, 2009, p. 228).

Física e materialmente, nada se modifica numa conversão. A mudança ocorre no âmbito espiritual. Quem experimenta a graça da irrupção de nova dimensão começa a caminhar por "dentro" das coisas. Percebe uma participação íntima com cada coisa a partir de um movimento de crescimento anterior e posterior a si mesmo. O que muda então é o ocular, a interpretação, o significado, o sentido das coisas? Não. O que se modifica é o que se compreende e experimenta por ocular, interpretação, significado e sentido. Então é uma subjetivação da experiência? Não. Ocorre realmente uma passagem, uma incorporação de pessoa numa nova ordem de coisas e incorporação de nova ordem de coisas na pessoa.

O processo de criatividade e con-criatividade não está pautado no fazer e produzir o novo, mas na irrupção do novo em todos os empenhos e desempenhos da experiência humana. Isso requer uma passagem.

Martin Buber (1995) descreve esse processo num tópico chamado "Entremeio".

Disse o Maguid de Mesritsch: - Coisa alguma deste mundo pode passar de uma realidade a outra, a não ser que antes vá ao nada, ou seja, à realidade de entremeio. Nessa altura é nada e ninguém consegue compreendê-lo, pois chegou ao nível do nada, como antes da criação. E então é recriado como novo ser, do ovo ao pintainho. O momento em que se consumou a destruição do ovo, e antes de ter-se iniciado o pintainho, ninguém pode compreender, porque ele é uma força anterior à criação e se denomina caos. Ocorre o mesmo com a semente que germina: não começa a germinar antes que se desfaça no solo e que seu ser seja destruído de modo a chegar ao nada, que é a etapa anterior à criação. Essa etapa é chamada sabedoria, ou seja, um pensamento despido de manifestação. E a partir daí, dá-se a criação como está escrito: "A todos eles fizeste com sabedoria" (p. 147).

Entremeio pode ser um espaço entre dois elementos; um instante entre dois momentos, um vão intermédio de passagem. Entremeio pode ser o adensamento do silêncio na madrugada, que vai se intensificando e ganhando corpo prenhe de si mesmo de tal modo que densifica a presença da escuridão e esgotamento da noite a ponto de poder explodir algo novo, nova luz, novo dia. Entremeio pode ser uma crise profissional, uma crise matrimonial, uma crise existencial etc. Todavia esse adensar que é ao mesmo tempo aniquilar-se e sumir, se esgotando numa doação completa, não é um algo entre algos. Um espaço entre espaços, um tempo entre tempos, um estágio da vida entre estágios. Tampouco

1 Cf. Agostinho, In Ioh. tr. 72 n. 3, PL 35, 1823; cf. Tomás de Aquino, S. Theol. I II q.113 a. 9. 
há um mero fluir ali. Parece antes dar-se uma interrupção da fluência. É o consumar-se e esmorecer de mundo. Esse esgotamento provoca um empreender e avançar que é primordialmente um retorno a uma “etapa anterior à criação", anterior aos dois polos que se opõem e se anulam.

A possibilidade de coparticipar dessa força anterior que se chama caos é co-criatividade, participar sendo o próprio processo criativo do novo.

\section{A dimensão é o espiritual - a coisa é o material}

O surgir de uma nova dimensão coincide com o surgimento de um novo si-mesmo. A categoria apropriada para qualificar esse processo é a experiência, pois ela supera tudo que se possa esperar ou imaginar de antemão. Segundo Rombach, surge ali novo conteúdo e nova determinidade, inusitados e inadiantáveis. Nova dimensão e individualidade coincidem no que se qualifica como idemidade.

A idemidade, onde se funde numa nova realidade, o indivíduo e sua dimensão, não surge por acaso, tampouco é um processo desenvolvido pelo método da vontade e decisão voluntarista. Há sempre nesses casos um longo itinerário de aprimoramento artesanal do universo que está mais próximo, no cuidado e cura do que é o entorno, mas com o olho nesse impulso prévio e ainda invisível de crescimento e elevação. O que é propriamente essa precedência e seu porvir não são determinados de antemão. Criatividade é o coração de criação. Co-criatividade é a idemidade entre coisa e si-mesmo, anterioridade e posterioridade da dimensão. Nos poderá ajudar a essa altura considerar como Mestre Eckhart, a quem remonta seguidamente a fenomenologia, considera esse processo a partir de sua abordagem da criatura. Em Eckhart criatividade tem usualmente o nome de espírito. Criatura é chamada de corpo, tempo e lugar.

As criaturas são corpóreas e decaem numa degeneração e enfado, por isso, ali não há crescimento. Quanto mais olho para um pano branco ou para a luz do sol, tanto mais meu olho se turva e se obscurece. Jamais existiu criatura tão bela nem tão nobre que se pudesse contemplá-la por um longo tempo e não se tornasse enfadonha. Mas conhecimentos espirituais possuem um crescimento que não tem fim. Quanto mais e melhor eu conheço coisas espirituais, tanto mais límpido e adequado torna-se meu sentido na direção do conhecimento (Eckhart, 2008, p. 151-152).

Crescimento infinito no processo do espírito remete a uma vida dentro de Vida, na fluência e co-participação de Vida, a grande Vida. Também no dizer eckhartiano encontra-se a degeneração e o enfado, a aniquilação e o nada. Há que se ressaltar sempre que esse movimento "negativo" em relação à criatura não coincide com a compreensão tradicional de ascese. Nunca e jamais trata-se de abdicação, renúncia, recusa, desprezo, ingratidão e revolta para com o imediato e natural, dado e pronto. $\mathrm{O}$ empuxo interno e o móvel do pensar ali é o acolhimento pleno, o aperfeiçoamento e elevação desse dom prévio. Quando alguém descobre ter sido dotado com aptidões e habilidades, com vocação para o fabrico do vinho, há que esmerar todo cuidado e diligência para o aperfeiçoamento dessa sua habilidade, observando e fazendo crescer esse movimento de vida ao seu grau máximo, implicando e aprimorando processos de procedência e de finalidade da habilidade. A distinção entre espírito e corpo no texto acima não se refere à atividades específicas do humano. Sempre estamos às voltas com o princípio da divisão. É no enfado, no esgotamento dessa materialidade que pode surgir a dimensão do espírito. Espírito só surge quando, no esgotamento das possibilidades materiais corpóreas de uma atividade, surge uma idemidade que dá novo sentido e nova realidade a todos os "elementos" componentes dessa região. Nessa hora, feliz hora, o homem sente-se ali como um peixe dentro d'água.

Por que o mergulho nessa idemidade do espírito é sem fim? Porque é redondo, começa e termina em cada momento. É redondo porque é uno, porque está na fluência da dinâmica da originaridade, profundidade e imensidão de vida. É possível percorrer uma cadeia de elevações dimensionais. Enquanto há vida há elevação.

Um encaminhamento de elevação próprio do humano, na idemidade com o princípio elementar de uma nova dimensão, sempre vem carregado de esperança e vida nova. É só a abertura de uma elevação que pode trazer transformação verdadeira e duradoura. Vicios humanos, vícios de caráter, desajustes psíquicos, desajustes sociais etc. só tem real transformação quando pelo esgotamento de uma elevação se alcança um novo patamar de vida, um novo si-mesmo.

Não se trata de uma mera inversão do direcionamento do fazer, que partia do homem para a coisa, e agora partiria da coisa para o homem. Elevar-se a uma escuta da coisa em questão a cada vez para um levar a efeito, realizar a potencialidade da própria coisa em questão. Das Ding dingt. Levar a potencialidade do mármore à sua elevação a Estátua de Apolo. Ali ainda não há concriatividade. "Nela age um Idem que não é nem um nem outro. E algo assim é bem concreto e bem possível e muito natural. "Natural", visto que o mundo dividido já pressupõe a unidade" (Rombach, 1995, p. 24).

A nova dimensão premia tudo que envolve com sua leveza e densidade significativa. Tem o caráter de ação do que os gregos chamavam de modo medial do verbo, não é passivo, nem ativo. Não é habilidade operacional do homem atuante nem é acaso do acontecer, mas apenas ato concriativo, onde as duas coisas perdem sua autoestabilidade e se fundem numa unidade ativa diversa, que se transforma em algo novo. Quando a tradição cristã concebe a natureza como um todo como "criação" atinge o ponto certo.

Uma tal vida indivisa, que unifica criador e criação, "não é um momento de descendência de Deus nem de sobreelevação da natureza, mas um momento de mergulho de volta no fundamento ori- 
ginário, que é e permanece o um indiviso e sem o qual as coisas não poderiam formar qualquer coesão, sejam elas Deus ou natureza, homem ou mundo, vivas ou mortas.

Rombach fala algo extraordinário aqui. Segundo ele talvez o maior milagre do ser humano ou a maior sorte e felicidade seja ter a possibilidade de mergulhar de volta para o fundamento originário, que consiste na indivisibilidade, e a partir dali gerar a si mesmo de novo.

Aqui novamente vemos semelhança com um dos temas centrais dos sermões alemães do Eckhart: O nascimento de Deus na alma.

No $n^{\circ} 23$ de suas "Conversações espirituais", sentado e rodeado por seus discípulos, Mestre Eckhart discute sobre as obras interiores e exteriores. Ali descreve uma cena onde alguém poderia imaginar-se num estado de tal tranquilidade que não sente qualquer impulso interior ou exterior para agir. Num estado de tal sossego que se funde na paisagem do nada. O outro extremo pode ser aqui imaginado também, apesar de não precisar ser mencionado por Eckhart, pela obviedade do ambiente: a sofreguidão da ação e o perder-se nas atividades exteriores. Eckhart vai ensinar a seus discípulos, portanto, que a virtude está no meio, na boa dosagem, equilibrada entre atividade interior e exterior, ora et labora...? Afinal todo exagero e extrapolação é prejudicial.

Vamos ouvir o que diz o Mestre:

... então deve ser forçado a alguma obra, seja interior ou exterior - pois o homem não deve largar-se como satisfeito em nada, por mais que pareça bom ou o seja - para que, quando ele se encontrar em forte pressão ou num estreitamento de si mesmo, que possa ter então a impressão de ser mais co-agido do de agir, que então aprenda a co-atuar com seu Deus (Eckhart, 1984, p. 139) 2* $^{*}$

Encontrar-se em forte pressão ou num estreitamento de si mesmo é quando as forças pessoais já não dão conta de levar adiante uma situação; onde as saídas começam a desaparecer, onde às vezes parece ter-se chegado ao fim da linha. Esse constrangimento descrito por Eckhart não é do homem voluntarista nem do homem preguiçoso, mas de um homem que trabalhou e trabalhou bem. De alguém que cresceu na habilidade de um afazer concreto na vida e cresceu com o afazer e com a própria vida. Nesse itinerário poderá chegar um momento em que se dá um afunilamento e um estreitamento das possibilidades desse afazer, um esgotamento das possibilidades. Essa é a hora de a onça beber água, a hora do adensamento do silêncio da madrugada, de recuar, aconchegar-se mais ao fundo do nascedouro do nada, no raso do chapado, na espera do inesperado. Há que haver uma grande concentra-

$2{ }^{*} \ldots$ so soll man sich gewaltsam zwingen zu einem Werk, sei's ein inneres oder ein äusseres - denn an nichts soll sich der Mensch genügen lassen, wie gut es auch scheint oder sein mag - damit, wenn er sich unter hartem druck oder Einengung seiner selbst so befindet, dass man eher der Eindruck gewinnen kann, dass der Mensch dabei gewirkt werde, als dass er wirke, der Mensch dann min seinem Gott mitzuwirken lerne. ção e nadificação aqui, um olhar e uma atitude, um resvalar e puxar para o que ainda resta do dentro, a suspensão de obra. É possível então que esse operário comece a sentir-se operação pura, verbo do fazer e do viver, verbo do iniciar e do criar, que comece a sentir-se co-agido (gewirkt werde). Começa a sentir-se parte de um princípio maior, anterior e mais amplo. Começa a fazer novamente tudo que fazia, mas já não é ele quem faz, adentra-lhe uma leveza e novidade, um alargamento da vastidão; ele é como um peixe dentro d'água, uma andorinha revoluteando, uma criança brincando, uma roda que gira sobre si mesma.

O que acontece numa feliz e rara hora dessas? Como diz Rombach: "Criativo, porém, só é aquele produzir que, junto com a coisa produzida cria igualmente uma nova dimensão para essa coisa e para coisas semelhantes” (Rombach, 1994, p. 15). Há muitas pessoas que experimentam essa travessia e irrupção. No fundo sabem que esse tipo de acontecimento é extremamente importante e essencial para a vida. É o fenômeno da co-criatividade, pelo qual o homem alcança como que um novo nascimento, mais elevado e conquista seu verdadeiro si-mesmo.

A co-criatividade é pois a irrupção de uma nova dimensão no afunilamento de um itinerário. Significa co-ação, agir-junto-com algum encaminhamento que é anterior, posterior que o sujeito da ação. É mais que largar-se, é mais que agir; é menos que largar-se, é menos que agir. Esse movimento pode ser sentido na cantiga Timoneiro de Paulinho da Viola:

\section{Não sou eu quem me navega \\ Quem me navega é o mar \\ É ele quem me carrega \\ Como nem fosse levar...}

Esse processo de descoberta de uma nova dimensão gera consigo uma elevação do status de vida em sua totalidade. Esse aprendizado "instantâneo" costuma trazer um incremento significativo de satisfação e contentamento, vem acompanhado de um sentimento de alegria e alívio, leveza e gratidão, vitalidade e novidade. $\mathrm{O}$ que esses pensadores descrevem nesse processo não é um acontecimento definitivo, é um itinerário de autoelevação. O próprio Deus é um movimento de crescimento, enquanto visto e experimentado pelo humano.

Toda criança experimenta a elevação de todo seu estatuto de vida quando um dia, de repente, depois de uma infinidade de tombos e reerguidas, começa a caminhar; equilibra seu corpo, se apruma e se estabelece dentro e no exercício de sua nova conquista. Conquista novo mundo. O mesmo processo se dá quando se aprende a andar de bicicleta, quando um dia se descobre e experimenta que para nadar não se deve lutar contra a água, mas entrar na mesma dinâmica e fluência da água e então aprende-se um outro modo de movimentação e tudo ganha um novo incremento. Esse acontecimento tem repercussão em todo o universo do ser e fazer dessa pessoa. Não é apenas o acréscimo de mais uma atividade entre outras... é uma elevação da totalidade 
de vida a um novo patamar e nível de experimentação e concretização. Toda elevação que acontece numa passagem de dimensão se dá pela criatividade e co-criatividade.

O homem novo, em seu novo patamar, é estabelecido e se estabelece numa nova relação para com o todo da realidade. Ali o homem não é apenas criativo mas co-criativo.

Um homem postado na co-criatividade - e esse é um homem novo - jamais irá dirigir-se às coisas, buscando realizar apenas suas próprias representações, mas buscará provocar também a autotranscendência das coisas e das situações, de modo que essas irão se mostrar dispostas a doar ao acontecer suas próprias forças, suas forças mais elevadas (Rombach, 1987, p. 127).

\section{Referências}

Buber, M. (1995). Histórias do Rabi. São Paulo: Perspectiva.

Cusa, N. (2002). A douta ignorância. Porto Alegre: Edipucrs.

Eckhart, M. (2009). Sermões alemães I. Petrópolis: Vozes.

Eckhart, M. (2008). Sermões alemães II. Petrópolis: Vozes.

Eckhart, M. (1994). O livro da divina consolação e outros textos seletos. Petrópolis: Vozes.

Rombach, H. (1987). Strukturanthropologie: "Der menschliche Mensch”. Freiburg; München: Karl Alber.

Rombach, H. (1991). Der kommende Gott: Hermetik - Eine neue Weltsicht. Freiburg im Breslau: Rombach Verlag.

Rombach, H. (1994). Der Ursprung: Philosophie der Konkreativität von Mensch und Natur. Freiburg im Breislau: Rombach Verlag.

Rombach, H. (1997). Strukturontologie. Eine Phänomenologie der Freiheit. Freiburg; München: Verlag Karl Alber.

Enio Paulo Giachini é Doutor em Filosofia pela Universidade Federal do Rio de Janeiro, Atualmente é Professor do Instituto de Filosofia São Boavenatura, FAE Centro Universitário (Curitiba/PR). Email: enio.giachini@bomjesus.br

Recebido em 23.01.2018

Aceito em 02.08.2018 